\title{
Chromosome 3q29 deletion with gastrointestinal malformation: a case report
}

\author{
Ma'in Masarweh
}

\begin{abstract}
Introduction: Most chromosome 3 deletions are associated with neuro-developmental and eye abnormalities. Here, we report a rare and unusual multiple congenital abnormality, including ano-rectal malformation, in conjunction with chromosome 3q29 segment deletion, which has not previously been reported.

Case presentation: A three-month-old female Jordanian baby presented with an absent anus and corneal opacities and was referred for further management after a diverting colostomy operation at the age of one day.

Conclusion: Chromosome 3q29 deletion is associated with additional abnormalities to neurological ones, such as ano-rectal malformations. We need to investigate a patient fully to find such hidden clinical features.
\end{abstract}

\section{Introduction}

Chromosome 3q deletion syndrome, 3q-syndrome, and monosomy $3 \mathrm{q}$ are all synonyms of the same clinical description, and it is considered an uncommon anomaly [1]. This condition is not associated with any antenatal abnormalities, and the birth history is uneventful in most patients [2]. Deletion of the long arm of chromosome 3 may present with variable phenotypes, consisting mainly of microcephaly, unusual facial appearance, eye abnormalities, deformed ears, and a delay in growth and development. A partial deletion of the long arm of chromosome 3, mainly the q23-q25 and q22-q23 bands, is associated with blepharophimosis-ptosis-epicanthus inversus syndrome (BPES), and most reported cases are linked to this deletion [3].

The major phenotypic features involve nearly all of the systems, including the head and neck (microcephaly, dolichocephaly, trigonocephaly, retro-micrognathia, large abnormally shaped posteriorly rotated and low-set ears, prominent or beaked nose, broad nasal bridge, and cleft lip and palate), the spine (13 thoracic vertebrae and scoliosis or kyphosis), the heart, and the nervous system [4]. It has been reported that some deletions are hereditary, such as the 3q23-q25 deletion, and some of them may be associated with female infertility $[3,5]$.

Correspondence: mmasarweh@khcc.jo

King Hussein Cancer Centre, Amman, Jordan

\section{Case presentation}

A three-month-old Jordanian female baby was vaginally delivered at full-term to a 25-year-old mother on her second pregnancy, the first being successfully carried past 20 weeks (G2P1). The baby's parents were healthy and non-related. She presented with a history of anorectal malformation for further management. She underwent sigmoid loop colostomy after 24 hours of birth outside our hospital. General examination of the baby upon presentation showed a few external abnormal features such as a small head, low-set ears, corneal opacities in both eyes, and a high-arched palate in addition to signs of dehydration and being underweight. An abdominal examination revealed ulcerated inflamed skin in the left lower quadrant around a prolapsing loop colostomy, with fluid stool content. A perineal examination showed a single orifice, with urine coming through it. No anal or vaginal orifices were seen (Figure 1), and the labioscrotal folds were under-developed. Her work-up showed that she was suffering from atrial septal defect (ASD), ventricular septal defect (VSD), a delay in mental development, corneal opacities, and cloacal ano-rectal malformation.

A micturating cysto-urethrogram confirmed the common channel of the deformity. Ultrasonography of the abdomen was normal. Skeletal survey and brain magnetic resonance imaging results were normal. A chromosomal analysis was carried out, involving 20 CTGbanded cells from two cultures, and five cells were 


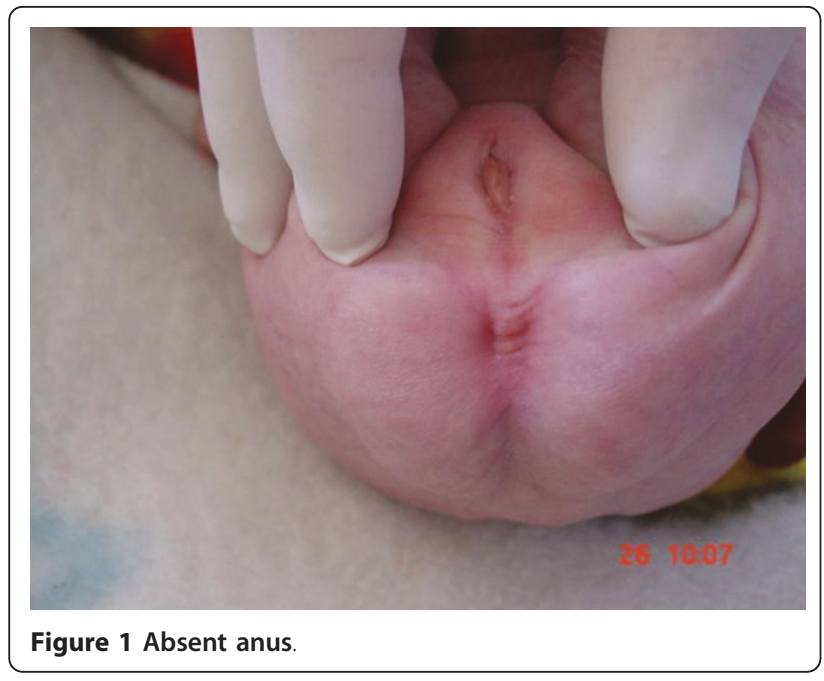

karotyped and photographed, showing 46,XX,del(3)(q29) (Figure 2).

Our patient was treated for the colostomy complication and, at the age of nine months, she underwent full repair of the cloaca through posterior saggital anorecto-vaginoplasty. Smooth post-operative recovery was achieved, and three months later the colostomy opening was closed. Her heart condition was stable over the three years of follow-up, the VSD and ASD reduced in

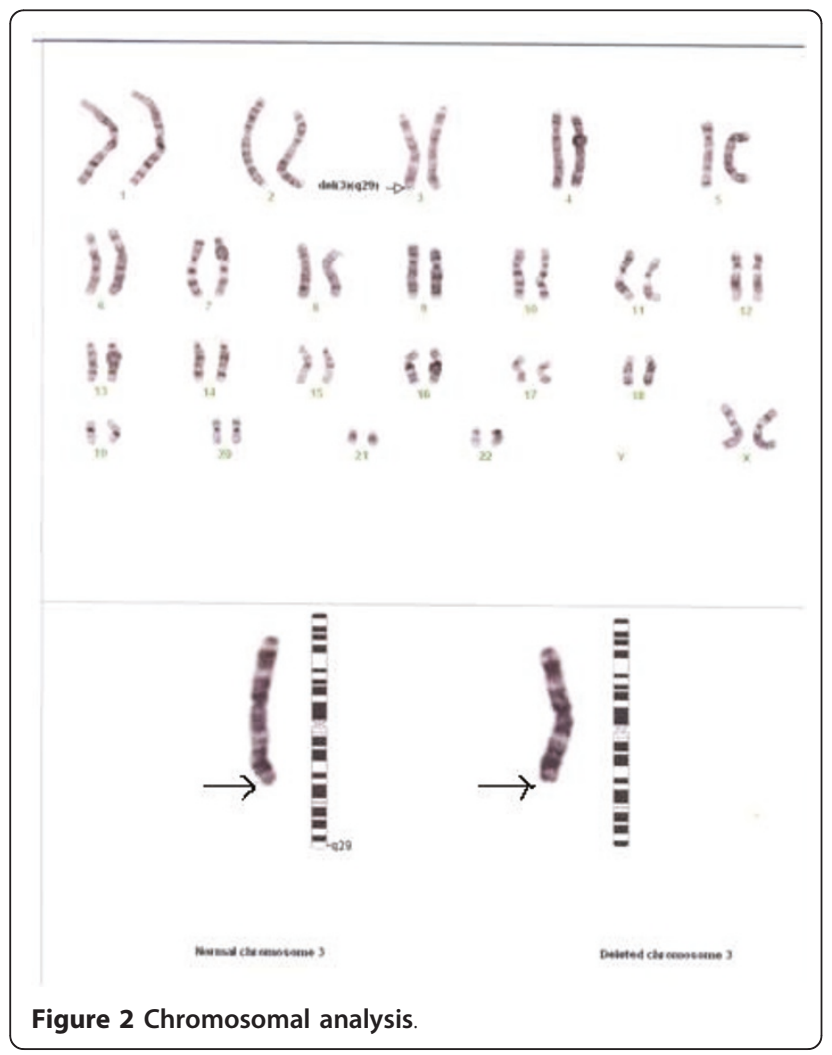

size, her corneal opacities did not progress, and she remained under the supervision of our ophthalmologist. Her mental development continued to grow slowly, and she is now able to speak a few words and stand up without support.

\section{Discussion}

Chromosome 3 deletions are rare anomalies [6], with deletions involving band 2 being more commonly reported, as mentioned by most reviewed reports. We found some case reports mentioning the association of this abnormality with the development of congenital diaphragmatic hernia [6,7] and enlarged penile size [8], in addition to the recognizable contiguous gene syndrome of deletion of 3q23 in BPES [9]. Another report by Cai et al. [10] described the unusual unilateral ptosis and absence of the epicanthus inversus, but the chromosomal study showed unbalanced translocation, 46, XX, $\operatorname{der}(7) t(3 ; 7)$ (q26-qter;q+), which resulted in trisomy for distal 3q.

Another report described new features of the deletion of 3q with progressive scoliosis, multiple skin pigmentations, and renal abnormalities [11]. A deletion similar to that in our patient was found in a case reported by Baynam et al. [12] but with different clinical features.

Here, our patient had an ano-rectal anomaly in addition to corneal opacities, which we could not find in any of the reports reviewed, including Ballif et al. in 2008 [4] or Willatt L et al. in 2005, which described the most up-to-date cases of 3q29 microdeletions in six patients with different phenotypic features [2]. It seems that these deletions are not consistent with any one type of clinical abnormality, and there might still be some other molecular factors that play a role in the development of the clinical symptoms of chromosome 3 deletions. Additional investigations using high resolution techniques, such as single nucleotide polymorphism or oligo arrays, are advised to confirm pure deletion of 3q29 and to exclude, for example, a chromosome translocation, and thus duplication of another chromosome adding to the phenotype. Unfortunately, these techniques are not available at our institution or in our country.

Our patient had been followed up for three years. Her development was very slow as compared to her sister, who was born two years later and who did not show any similar abnormality.

\section{Conclusion}

Chromosome 3q29 deletions are associated with other abnormalities such as ano-rectal malformations, and not only the previously reported neurological abnormalities. We need to investigate a patient fully to find such hidden clinical features. The next step is to understand the 
exact molecular mechanisms of this disease. More research is required to identify if there is a mode of inheritance in chromosome 3 deletions, as in BPES. This will help to explain why these patients vary in their clinical features.

\section{Consent}

Written informed consent was obtained from the patient's father for publication of this case report and any accompanying images. A copy of the written consent is available for review by the Editor-in-Chief of this journal.

\section{Competing interests}

The author declares that they have no competing interests.

Received: 15 May 2010 Accepted: 5 July 2011 Published: 5 July 2011

\section{References}

1. Alvarado M, Bocian M, Walker AP: Interstitial deletion of the long arm of chromosome 3: case report, review, and definition of a phenotype. Am J Med Genet 1987, 27(4):781-786.

2. Willatt L, Cox J, Barber J, Cabanas ED, Collins A, Donnai D, FitzPatrick DR, Maher E, Martin H, Parnau J, Pindar L, Ramsay J, Shaw-Smith C, Sistermans EA, Tettenborn M, Trump D, de Vries BB, Walker K, Raymond FL: 3q29 microdeletion syndrome: clinical and molecular characterization of a new syndrome. Am J Hum Genet 2005, 77(1):154-160.

3. Ko WT, Lam WF, Lo FM, Chan WK, Lam TS: Wisconsin Syndrome in a patient with interstitial deletion of the long arm of chromosome 3: further delineation of the phenotype. Am J Med Genet 2003, 120A(3):413-417.

4. Ballif BC, Theisen A, Coppinger J, Gowans GC, Hersh JH, Madan-Khetarpal S, Schmidt KR, Tervo R, Escobar LF, Friedrich CA, McDonald M, Campbell L, Ming JE, Zackai EH, Bejjani BA, Shaffer LG: Expanding the clinical phenotype of the $3 q 29$ microdeletion syndrome and characterization of the reciprocal microduplication. Mol Cytogenet 2008, 1:8.

5. Nguyen T, McDonnell CM, Zacharin MR: Primary ovarian failure and deletions of the long arm of chromosome 3. J Pediatr Endocrinol Metab 2005, 18(10):1013-1017.

6. Bernnan P, Croaker GD, Heath M: Congenital diaphragmatic hernia and interstitial deletion of chromosome 3. J Med Genet 2001, 38(8):556-558.

7. Bollman R, Kalache K, Mau H, Chaoui R, Tennstedt C: Associated malformations and chromosomal defects in congenital diaphragmatic hernia. Fetal Diagn Ther 1995, 10(1):52-59.

8. Nguib KK, al-Awadi SA, Farag TI, Mohammed FM: Penile enlargement in 3q23-q25 deletion syndrome. Am J Med Genet 1990, 36(3):361-362.

9. Costa T, Pashby R, Huggins M, Teshima IE: Deletion $3 q$ in two patients with Blepharophimosis-ptosis-epicanthus inversus syndrome (BPES). $J$ Pediatr Ophthalmol Strabismus 1998, 35(5):271-276.

10. Cai T, Tagle DA, Xia X, Yu P, He XX, Li Ly, Xia JH: A novel case of unilateral blepharophimosis syndrome and mental retardation associated with de novo trisomy for chromosome 3q. J Med Genet 34(9):772-776.

11. Okada N, Hasegawa T, Osawa M, Fukuyama Y: A case of de novo interstitial deletion 3q. J Med Genet 1987, 24(5):305-308.

12. Baynam G, Goldblatt J, Townshend S: A case of $3 q 29$ microdeletion with novel features and a review of cytogenetically visible terminal $3 q$ deletions. Clin dysmorphol 2006, 15(3):145-148.

doi:10.1186/1752-1947-5-285

Cite this article as: Masarweh: Chromosome $3 q 29$ deletion with gastrointestinal malformation: a case report. Journal of Medical Case Reports 2011 5:285.

\section{Submit your next manuscript to BioMed Central and take full advantage of:}

- Convenient online submission

- Thorough peer review

- No space constraints or color figure charges

- Immediate publication on acceptance

- Inclusion in PubMed, CAS, Scopus and Google Scholar

- Research which is freely available for redistribution

Submit your manuscript at www.biomedcentral.com/submit 